\title{
Dancing to Darwin's tune
}

\section{The Singing Neanderthals: The Origins of Music, Language, Mind and Body \\ by Steve Mithen \\ Weidenfeld \& Nicolson: 2005. 272 pp. $£ 20$}

\section{W. Tecumseh Fitch}

The years after the publication in 1859 of Darwin's On the Origin of Species were full of turmoil. Darwin found a powerfully placed and unyielding opponent in the Oxford linguist Max Müller. The battle lines were clearly drawn: Müller (like many contemporaries) was willing to grant natural selection a role in generating animal form, but he thought it incapable of explaining human evolution, particularly the quintessentially human trait of language. Müller's core critique concerned the lack of plausible precursors of language. $\mathrm{He}$ ruthlessly criticized Victorian ideas about the origin of language, coining derogatory nicknames for them, such as the 'bow wow' and 'ding dong' theories, which are still used today.

Darwin had cautiously omitted virtually all mention of human evolution in $\mathrm{On}$ the Origin of Species, but he took on the problem of language evolution in his 1871 book The Descent of Man, and Selection in Relation to Sex. Like most subsequent theorists, Darwin recognized that something as complex as human language could not have sprung into existence fully formed, but must have passed through some intermediate phase (today termed a 'protolanguage'). Recognizing that music is a human universal, rendered peculiar by its lack of any obvious survival function, he elaborated on an idea briefly mentioned by Jean-Jacques Rousseau that protolanguage was similar to music, and suggested that "the rhythms and cadences of oratory are derived from previously developed musical powers. He dismissed the converse idea, put forward by Denis Diderot and Herbert Spencer, that music derives from speech, as being contrary to basic evolutionary principles. Darwin argued, by analogy with birdsong, that early musical capacities were driven by sexual selection: "Musical notes and rhythm were first acquired by the male or female progenitors of mankind for the sake of charming the opposite sex."

Despite recent scholarly interest in the evolution of language, The Singing Neanderthals by Steven Mithen is the first book-length exposition of Darwin's 'musical protolanguage' hypothesis that I have seen. Mithen, a professed non-musician, mounts an enthusiastic and often impressive defence of Darwin's hypothesis, covering a wide variety of fascinating topics.

Mithen first takes aim at Spencer's idea that music is simply a non-adaptive by-product of spoken language - a viewpoint memorably expressed by Steven Pinker in his 'music as cheesecake' hypothesis in How the Mind Works (W. W. Norton, 1997). Mithen argues that the power of music over human emotions and behaviour is inconsistent with this hypothesis. $\mathrm{He}$ ably summarizes current proposals for adaptive functions of music, covering its roles in childcare, group cohesion, competition and

laid out by Darwin more than a century ago. "Hmmmm", indeed.

The book's biggest weakness is that Mithen's enthusiasm for the musical protolanguage hypothesis sometimes prevents him from frankly acknowledging its problems. This is most clear in his treatment of the neuroscience of music. He reviews brain-lesion studies that indicate a separation of musical and linguistic circuitry in the brain, providing evidence against the idea that music is simply a byproduct of language. But he fails to review more recent brain-imaging work that paints a more complex picture of partly overlapping neural circuitry for music and language. His discussion of potential fossil cues to the evolution of song and speech is outdated and incorrect in several places, and his treatment of potential parallels between music and animal vocalizations is almost entirely limited to primates, ignoring a wider range of animal data, such as birdsong, that is relevant to the evolution of music. So although the book provides broad coverage of supporting data, readers seeking a balanced overview will have to turn to the specialist literature.

These criticisms aside, the book is extremely well-written, and Mithen's dear and infectious enthusiasm make it a good introduction for nonspecialists interested in the topic. I can recommend it to anyone interested in the biology and evolution of music or

mate choice. A childcare function seems the most convincing, as parents in all human cultures sing to their children, and experimental work has shown that mothers' lullabies and play songs have an important role in regulating infant arousal. But each of the other alternatives receives some support from Mithen's review. $\mathrm{He}$ has assembled a considerable body of data and argument that modern-day Müllers, critical ofDarwin's proposal of a musical protolanguage, will need to answer.

Mithen then builds on his expertise in human palaeontology and archaeology to develop a detailed picture of this hypothetical musical protolanguage, which he dubs "Hmmmm", for "holistic, manipulative, multimodal, musical and mimetic". Although Mithen's scenario is far more detailed than previous accounts, I was surprised and disappointed that nowhere in this long volume, rich with footnotes, does he acknowledge that the core idea of the book is Darwin's. He cites The Descent of Man, and some relevant passages are even quoted in passing, but Mithen seems intent on daiming the musical protolanguage hypothesis as his own. The uninformed reader might easily finish the book without realizing that the central thesis of the book was concisely language - and particularly to readers interested in Darwin's idea that music constitutes an ancient and important form of human communication, intertwined with, but independent from, language.

W. Tecumseh Fitch is in the School of Psychology, University of StAndrews, St Andrews,

Fife KY16 9JU, UK.

\section{DARWIN IN FICTION}

Darwin's life and work has also inspired two recentnovels.

In This Thing of Darkness (Review, ET7.99), Harry Thampson focuses on the relationship between Charles Darwin and Robert Fitzroy, captain of The Beagle, and the origins of Darwin's theory of evolution and the religious debate it sparked. This fictionalized biography was longlisted for the 2005 Man Booker Prize.

John Darnton's The Darwin Conspiracy (Knopf, \$24.95) is a novel with a darker secret, told through three intertwined narratives. Two modem-day scholars trace Darwin's research path and also uncover the diaries of Darwin's daughter Lizzie. 